\title{
Effect of sulphur dioxide on the enzyme activity of the alveolar macrophage of rats
}

\author{
DAVID H. BARRY and LIONEL E. MAWDESLEY-THOMAS \\ Department of Pathology, Huntingdon Research Centre, Huntingdon
}

\begin{abstract}
Adult rats were exposed to sulphur dioxide to induce hypersecretion of mucus and so increase the amount of mucus reaching the alveoli. The comparative activity of four lysosomal hydrolytic enzymes was studied histochemically in free alveolar cells, thought to be macrophages, from the lungs of the exposed and control animals. Although the activity of $\beta$-glucuronidase, $\beta$-galactosidase, and $\mathrm{N}$-acetyl- $\beta$-glucosaminidase appeared increased in some free alveolar cells in the peribronchiolar region, a marked increase of acid phosphatase activity was seen in the free alveolar cells throughout the lung parenchyma. It is suggested that in rats acid phosphatase in alveolar macrophages is connected with the catabolism and removal of mucopolysaccharide and increases in response to the extra amount of mucus reaching the alveoli after respiratory irritation with sulphur dioxide.
\end{abstract}

Bronchitis has been simulated in rats by exposing them to sulphur dioxide (Reid, 1963). The hypersecretion of mucus results in an increased amount of mucus reaching the alveoli, which can often be seen completely filling the alveolar spaces when stained by the periodic acid Schiff method. The increase in mucus content of the lung may be derived from an increased number of mucussecreting glands (Reid, 1963) or more likely, initially, of hyperactivity of the cells already present. The effect of sulphur dioxide on the mucus-secreting cells of the respiratory tract has been reported (Mawdesley-Thomas and Healey, 1969). The removal of the accumulated mucus from the alveoli is important if total airway obstruction is to be avoided. The removal of mucus by the alveolar macrophages has been reported by McCarthy, Reid, and Gibbons (1964) after intraalveolar inoculations of a range of mucoid substances.

Phagocytosis by alveolar macrophages has been investigated at the electron microscope level (Karrer, 1958, 1960) and the invagination process has been described. In view of the evidence supporting the removal of mucus by the alveolar macrophage, it was decided to investigate some of the lysosomal hydrolase activities in normal rats and in rats irritated with sulphur dioxide. It was thought that, as the alveolar macrophages were equipped for mucopolysaccharide catabolism, an increase in mucus may have induced a corre- sponding increase in the activity of the enzymes involved.

\section{MATERIALS AND METHODS}

Twelve male and 12 female rats (Carworth Europe strain), each weighing $200 \mathrm{~g}$., were exposed to 300 parts per million concentration of sulphur dioxide for 6 hours on 10 consecutive days. ${ }^{1}$ Control rats were placed in similar chambers but allowed to breathe air.

Immediately after the final exposure period all the rats were killed by an intraperitoneal injection of sodium pentobarbitone, the thorax was opened and the trachea exposed. An aqueous $0.5 \%$ solution of polyethylene glycol 20 was introduced into the trachea and the lungs were inflated until they just filled the thoracic cavity (Barry and Robinson, 1969a). The thoracic viscera were then dissected out and quenched in hexane pre-cooled to $-75^{\circ} \mathrm{C}$. in a cardice acetone mixture. Fresh $8 \mu$ sections were cut on a Bright's cryostat at $-15^{\circ} \mathrm{C}$. and air-dried at $6^{\circ} \mathrm{C}$. Acid phosphatase activity was demonstrated by the lead precipitation technique of Gomori (1950) as modified by Lake (1966) and the azo coupling method of Burstone (1961). $\beta$-glucuronidase was demonstrated by the methods of Seligman, Tsou, Rutenburg, and Cohen (1954) and Hayashi, Nakajima, and Fishman (1964). $\beta$-galactosidase was demonstrated by the method of Rutenburg, Rutenburg, Monis, Teague, and

These concentrations of sulphur dioxide bear no relation to air pollution in London. The average conzentration over 10 years up to 1964 was $0.35 \mathrm{ppm}$ and the highest hourly concentration rose only to $5.6 \mathrm{ppm}$ (Commons and Walter, 1967). 

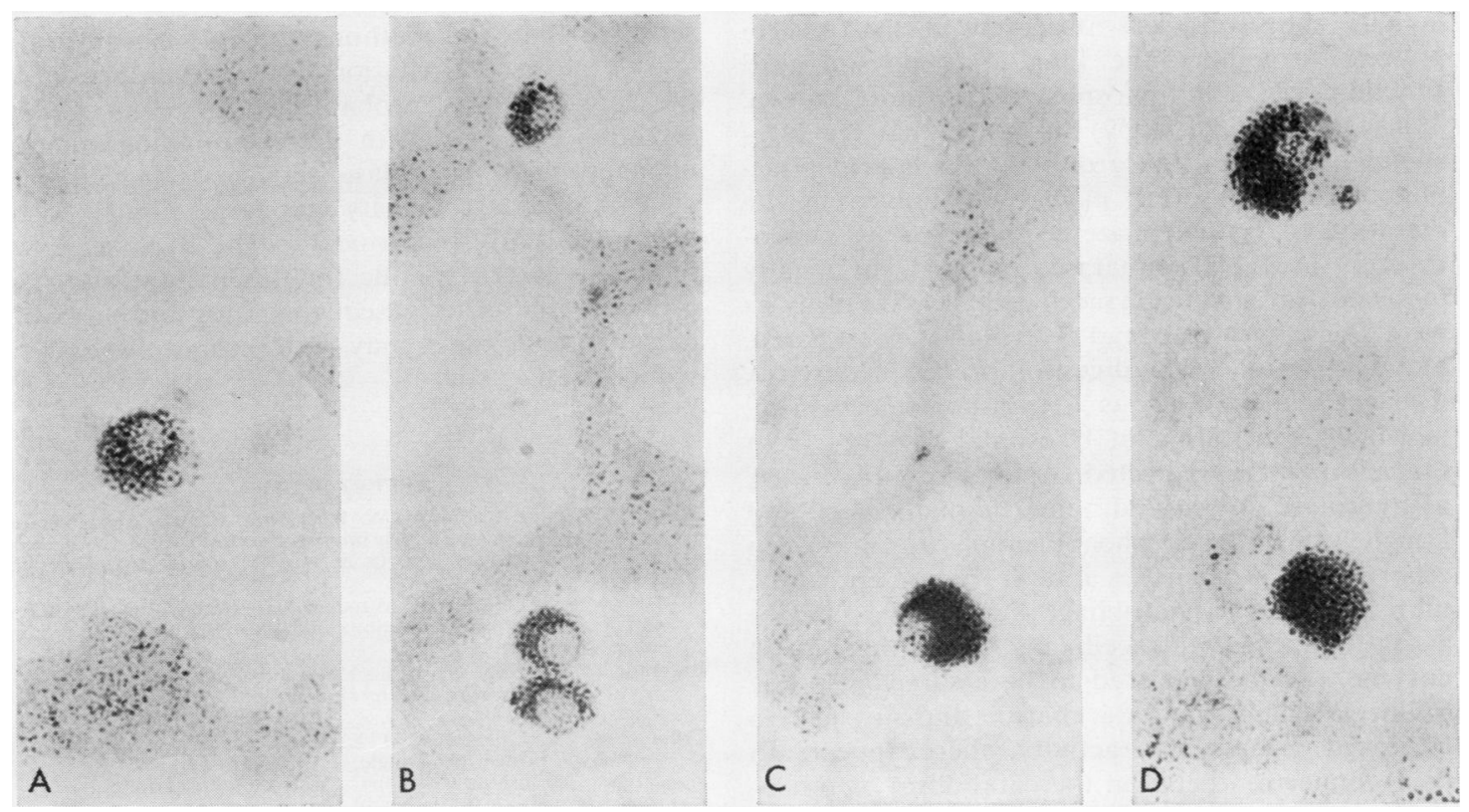

FIGURE. Acid phosphatase activity in alveolar macrophages demonstrated by the azo coupling method: $(A$ and $B)$ from control rats; $(C$ and $D)$ from rats exposed to sulphur dioxide.

Seligman (1958), post-coupling with fast blue B after an overnight incubation. $\mathrm{N}$-acetyl- $\beta$-glucosaminidase was demonstrated by the method of Pugh and Walker (1961), the sections being pre-rinsed in acetone at $-10^{\circ} \mathrm{C}$. for 15 seconds. Control sections of liver and kidney were incubated with the lungs for each enzyme system examined. The amount of enzyme activity was assessed by subjective evaluation of the cells.

\section{RESULTS}

Enzyme activity of the four systems studied was observed in free alveolar cells from the control animals although $\beta$-galactosidase and $\mathrm{N}$-acetyl- $\beta$ glucosaminidase appeared weakly active. All the free alveolar cells from the treated animals showed an increased activity of acid phosphatase (Figure) but the activity of the other three enzyme systems appeared increased only in some free cells adjacent to bronchi.

\section{DISCUSSION}

Irritation of the respiratory tract by sulphur dioxide causes hypersecretion of mucus (Reid, 1963). The combination of excess mucus and reduced ciliary action (Dalhamn, 1956) causes a backflow of mucus into the lung parenchyma. It has been suggested that this mucus is removed by the alveolar macrophages (McCarthy et al., 1964). The available evidence supports this suggestion, as pinocytosis ${ }^{2}$ occurs when macrophages are placed in an appropriate medium (Cohn and Fedorko, 1969) and they also contain the necessary enzymes of mucopolysaccharide catabolism. The present study did not include electron microscopic investigation, which made the complete identification of macrophages impossible. The free alveolar cells studied were, however, thought to be macrophages.

Although acid phosphatase is present in type II alveolar cells (granular pneumocytes), it appears stronger in alveolar macrophages (Barry and Robinson, 1969b). No increase of the mucopolysaccharide catabolizing enzymes investigated in alveolar macrophages was seen in the treated animals with the exception of some cells in the peribronchiolar region. This may have indicated an accumulation of mucus in this area, but as the peribronchial macrophages often appear larger and more numerous than the intra-alveolar macrophages, the increase may have been merely apparent. The increase in acid phosphatase

2Pinocytosis is ingestion of surrounding fluid by a cell. Local invagination of the plasma membrane completely surrounds a minute drop of fluid, which is thus engulfed by cytoplasm, forming a vesicle. 
activity, however, was observed in the macrophages throughout the lung. The physiological function of acid phosphatase is not known, although de Duve (1959) suggested that the lysosomal hydrolases, the group to which acid phosphatase belongs, were probably involved in the digestion of foreign material engulfed by phagocytosis. Acid phosphatase is not specifically involved in mucopolysaccharide catabolism as were the other lysosomal hydrolases investigated, and its function in the digestion process is obscure. The enzyme may act as a transport mechanism, in which case release of lysosomal enzymes from the cell might be expected. Apart from the release of hydrolase in cultured bone rudiments (Fell and Dingle, 1963), this phenomenon has not been reported in macrophages and, in the present study, the increased macrophage acid phosphatase activity appeared intracellular. As the increase in enzyme activity appeared to be a direct response to increased mucopolysaccharide and not just to increased macrophage activity, there appears to be a connection between the catabolism of mucopolysaccharide and the function of acid phosphatase in this situation. Leake, Gonzalez-Ojeda, and Myrvik (1964) found, biochemically and histochemically, that lysosomal acid phosphatase and $\beta$-glucuronidase activity was much greater in alveolar than in peritoneal macrophages. If these results indicate the functional requirements of the cells, they again indicate that acid phosphatase, although not specific, must be connected with the catabolism of mucopolysaccharide in the alveolar macrophage.

The reasons for the lack of visible increases in the other lysosomal hydrolases studied were more difficult to explain. Cohn and Fedorko (1969) found that, when macrophages were cultured in vitro, the number and activity of lysosomes increased during the first 72-hour period. Acid phosphatase increased by a factor of about 37 , while $\beta$-glucuronidase only increased by a factor of about 8. As the lysosomes appear to increase in response to the in vitro environment, it is quite probable that an in vivo environment of increased mucus would produce a similar result. In this event the small relative increase in $\beta$-glucuronidase would probably not be differentiated by histochemical procedures as the histochemical methods for $\beta$-glucuronidase, $\beta$-galactosidase, and $\mathrm{N}$-acetyl- $\beta$-glucosaminidase appear less sensitive than the methods for acid phosphatase.

The effects of irritation by sulphur dioxide on the lungs of rats probably consisted of hypersecretion of mucus with a corresponding increase in macrophage hydrolase activity, of which only acid phosphatase activity was large enough to be demonstrated histochemically. The hypersecretion of mucus is not specific for this irritant and it is probable that other gaseous irritants and probably particulate irritants may well produce the same sequence of events.

\section{REFERENCES}

Barry, D. H., and Robinson, W. E. (1969a). Enzyme histochemical studies on rat lungs. 1. An improved technique for the demonstration of enzyme activity in alveolar tissue. Histochem. J., 1, 497.

(1969b). Enzyme histochemical studies on rat lungs. 2. Normal enzyme distribution in the alveolar tissue of the mature lung. Histochem. J., 1, 505.

Burstone, M. S. (1961). Histochemical demonstration of phosphatases in frozen sections with naphthol AS-phosphate. J. Histochem. Cytochem., 9, 146.

Cohn, Z. A., and Fedorko, M. E. (1969). Lysosomes in Biology and Pathology. Edited by Dingle, J. T., and Fell, H. B. NorthHolland Publishing Company, Amsterdam and London.

Commins, B. T., and Waller, R. E. (1967). Observations from a tenyear-study of pollution at a site in the City of London. Atmospheric Environment, 1, 49.

Dalhamn, T. (1956). Mucous flow and ciliary activity in the trachea of healthy rats and rats exposed to respiratory irritant gases. Acta physiol. scand., 36, Suppl. 123.

de Duve, C. (1959). The function of intracellular hydrolases. Exp. Cell. Res., Suppl. 7, p. 169.

Fell, H. B., and Dingle, J. T. (1963). Studies on the mode of action of excess vitamin A.6. - Lysosomal protease and the degradation of cartilage matrix. Biochem. J., 87, 403.

Gomori, G. (1950). An improved histochemical technic for acid phosphatase. Stain Technol., 25, 81 .

Hayashi, M., Nakajima, Y., and Fishman, W. H. (1964). The cytologic demonstration of $\beta$-glucuronidase employing naphthol ASB1 glucuronide and hexazonium pararosanilin. J. Histochem. Cytochem., 12, 293.

Karrer, H. E. (1958). The ultrastructure of mouse lung: The alveolar macrophage. J. biophys. biochem. Cytol., 4, 693.

(1960). Electron microscopic study of the phagocytosis process in lung. J. biophys. biochem. Cytol., 7, 357.

Lake, B. D. (1966). The histochemistry of phosphatases: the use of lead acetate instead of lead nitrate. J. roy. micr. Soc., 85, 73.

Leake, E. S., Gonzalez-Ojeda, D., and Myrvik, Q. N. (1964). Enzymatic differences between normal alveolar macrophages and oil-induced peritoneal macrophages obtained from rabbits Exp. Cell Res., 33, 553.

McCarthy, C., Reid, L., and Gibbons, R. A. (1964). Intra-alveolar mucus-removal by macrophages: with accumulation. J. Path. Bact., 87, 39.

Mawdesley-Thomas, L. E., and Healey, P. (1969). The quantitative evaluation of experimental chronic bronchitis. Amer. Rev. evaluation of experir
resp. Dis., $100,231$.

Pugh, D., and Walker, P. G. (1961). The localization of N-acetyl- $\beta$ glucosaminidase in tissues. J. Histochem. Cytochem., 9, 242.

Reid, L. (1963). An experimental study of hypersecretion of mucus in the bronchial tree. Brit. J. exp. Path., 44, 437.

Rutenburg, A. M., Rutenburg, S. H., Monis, B., Teague, R., and Seligman, A. M. (1958). Histochemical demonstration of $\beta$-D galactosidase in the rat. J. Histochem. Cytochem., 6, 122.

Seligman, A. M., Tsou, K. C., Rutenburg, S. H., and Cohen, R. B. (1954). Histochemical demonstration of $\beta$-D-glucuronidase with a synthetic substrate. J. Histochem. Cytochem., 2, 209. 